\title{
(Re)counting the high cost of predatory publishing and the effect of a neoliberal performativity culture
}

\section{Suriamurthee Moonsamy Maistry}

\author{
School of Education, University of KwaZulu-Natal, Pinetown, South Africa \\ maistrys@ukzn.ac.za \\ http://orcid.org/0000-0001-9623-0078
}

(Received: 8 June 2018; accepted 12 February 2019)

\begin{abstract}
In this self-critical account, I engage the concepts of critique and judgement and why they are crucial for protecting and maintaining the integrity of academia and scholarship. I argue that a naive or ignorant academic is a somewhat paradoxical position to assume given that academia is necessarily a critical space that demands astuteness and constant vigilance. I contend that blissful ignorance is a fragile justification for the neglect of due diligence as it relates to the selection of locales for knowledge dissemination. I engage the tenets of self-study and critical autoethnography to reflect on my practice as an academic and the consequences of my own poor judgement, not as an act of arrogant disclosure, but with a view to embracing this "elephant in the national academic room" and also bringing to the fore, other "frail" current knowledge vetting processes. The article draws on a Žižekian notion of perverse analysis with the view to evoke a primal confrontation of a particularly sensitive issue. I draw attention to the gravity of the act of predatory publishing and its almost irrevocable consequences. I also reflect on my grief, trauma, guilt, and shame of this self-inflicted academic reputational mutilation, and the arduous task ahead of rebuilding my academic integrity. I hope that this paper might serve to intensify our alertness to the potential new perils that present in the neoliberal research productivity-driven higher education space where online publishing and open access have become common place, and where "opportunities" to transgress and expose oneself to risk present themselves on a daily basis, often with welldisguised "authenticity." Finally, I reflect on my public exposé of personal flaw and its restorative effect of a necessary humility in the academic space.
\end{abstract}

Key words: predatory publishing, knowledge vetting, judgement

\section{Introduction}

As a point of entry into scripting this exposé, I want to declare upfront and without condition, my assumption of full responsibility for the choices I made in the period 2012 to 2014, a period in which I published five articles with Kamla-Raj Enterprises (KRE) - a publisher that has been identified as a predatory publisher. While the ensuing discussion illuminates the circumstances under which this occurred, I do not for one moment exonerate myself from blame or responsibility. I am acutely aware of the ludicrousness of claiming, as academic, blissful oblivion or naivety. I contend that a naive and ignorant academic sounds, and is, 
oxymoronic to say the least. Academics are expected to be astute intellectuals, inherently critical and constantly suspicious, possessing robust scientific publishing literacy (see Beall, 2013), competences I had clearly not developed adequately at the time. It follows that pleading naivety and ignorance is a fragile argument, given my own critique of how the neoliberal performativity agenda might alter the behaviour of university academics (Maistry, 2012, 2015). I must admit that I blindly fell into this neoliberal trap, the consequences of which have been dire indeed. A sexually perverse, profanity-infused expression that captures lasting reputational damage reads as follows: "You f*ck one goat." The expression has its origins in the ancient practice of bestiality where some men exercised their proclivity for inserting their "junk" into farm animals. Žižek's $(2004,2011)$ notion of shared obscene solidarity has resonance here. He suggested that instead of invoking a postmodern political correctness in dealing with awkward, uncomfortable, highly sensitive issues that present in our social lives, we might well consider subpoenaing our natural, primal instincts through explicit and authentic engagement as opposed to false congenialities. This kind of engagement might have a diffusing effect, a full explanation of which is presented in later discussion in this paper. In returning to the goat analogy, the morbidity and horror of this act overshadows all previous or subsequent good deeds that one may do. It is a lifelong burden that the offender has to carry. This is a compelling analogy because it speaks powerfully to the full gravity and intensity of the subsequent repercussions for me, as well as for the various other subjects (including my research students and coauthors) who might have become collateral damage as a result of their association with me.

In this article, I explore key learning points for my own practice as higher education pedagogue, as researcher and writer, and as postgraduate research supervisor tasked with overseeing the knowledge creation process of advanced research degree (master's and doctoral) students. In attempting to fulfil this brief, I initially focus on the issue of judgement in academia, in particular, the academic peer-review or peer-evaluation system (Lamont, 2009). I deal with the notion of judgement on two levels. Firstly, I engage a discussion of how critique and judgement is an under discussed yet fundamental aspect that governs one's work in the academic space, and why a deliberative teaching (and profound learning) thereof is necessary-especially at the master's and doctoral levels, and in the mentorship of novice academics. I then proceed to reflect on a personal account of poor judgement and the profound consequences that have arisen from this. I also offer an analysis of how a systemic neoliberal performativity culture in the South African higher education context has contributed to a misguided rationale for knowledge production and dubious dissemination locales.

\section{A brief methodological note}

Methodologically, I invoke the tenets of self-study and critical autoethnography (Ellis, Adams, \& Bochner, 2011) to reflect on my practice as an academic and the consequences of my own poor judgement. I reflect on how a "seemingly mundane" occurrence became life changing (Boylorn \& Orbe, 2014, p. 21); the usual, normal act of writing up and despatching an article, in this instance, has left me and my associates exposed and vulnerable. I invoke 
Boylorn \& Orbe's notion of "verisimilitude of experience" that might render as authentic, my narrative exposition of personal crisis (2014, p. 20). It offers space for what I describe as a rich yet sober introspective - a rekindling of receptiveness and humility that had become somewhat benign. Anguish, distress, and excruciating discomfort that accompany a process of self-exposure and self-induced vulnerability are natural psychological reactions. Allowing myself to experience and work through this emotionally unsettling, self-effacing milieu was necessary given that it served as premise towards an emerging transcendental growth.

Self-study as methodological strategy has particular appeal and, while this methodological approach has initially struggled to gain traction and has been unfairly benchmarked against the pure sciences in terms of validity and reliability regimes, it has in recent years witnessed exponential growth, both in terms of the raw numbers of pedagogues who have seen and applied its tenets, as well as the nuanced, creative rigorous protocols that have emerged from the field itself (Lassonde, Galman, \& Kosnick, 2009). The ontological recognition of the implicated nature of the self in practice affords self-study researchers the space to construct themselves and their practice as abundant oasis, as rich epistemological resource (Lassonde et al., 2009). This methodological wellspring invites an eclectic dialectic between theory, practice, and self - fertile ground for rampant rhizomatics, a spontaneous eruption of ideas and questions that trigger other ideas and questions (Deleuze \& Guattari, 1987) as they relate to development and advancement in all three of these critical dimensions. In an attempt to invoke the scholarly principle of trustworthiness, I have drawn on colleagues in my school (of education) to offer critical comment on my analysis of this aspect of my practice as academic at in-house seminar platforms, generative spaces where my analyses have been interrogated, challenged, and refined.

\section{A watershed moment}

In setting a brief but necessary context, I draw attention to what might be deemed a watershed moment in the history of international and local scholarship and academic publishing — the first public exposé in 2010 by Jeffrey Beall, academic librarian at the University of Colorado Denver, of a blacklist of predatory journals and publishers. In fact, Beall noted that his initial 2010 release, comprising 18 publishers, attracted "almost no attention" from the scholarly world, but it was his more comprehensive 2011 (23 publishers) and 2013 lists, which had grown to 225 publishers (2013, p. 87), that rocked the international academic world. Predatory publishers can be described as unscrupulous, expedient, and opportunistic publishing houses that are driven by a profit motive. While profit in itself might be argued as a legitimate objective of any business, it becomes somewhat problematic when the traditional, accepted services of a business (predatory publishing houses, in this instance) are not provided to the buyers of such services.

Editorial and publishing services and the subjection of submitted articles to rigorous peer review, standard best practice in the world of knowledge production and dissemination, are ignored or neglected. In fact, upfront payment to such journals is an unconditional guarantee of acceptance of submitted articles. The publishing house benefits from generating easy 
money by offering limited or no peer review, while authors "benefit" from quick and easy publication. Internationally, Beall's revelations have generated widespread reaction, including advice pieces for authors (see, amongst others, Bowman, 2014; Miller \& DeBerg, 2017; Seigel, 2018).

In the South African higher education context, this unsavoury publication practice had started to gain traction but, once this was exposed, it created much heated, although somewhat delayed consternation in the South African higher education research community and, one might argue, a rather lethargic response from the Department of Higher Education and Training (DHET). To its credit, though, the community did eventually respond, commissioning a study, led by Johan Mouton, into the prevalence of predatory publishing in South Africa. The resulting report estimated the existence of 23,400+ journals at that point (Mouton \& Valentine, 2017). While it is not the focus of this article to unpack the details of the report, the evidence therein is quite damning and will certainly have telling effects on South African higher education institutions and individuals implicated.

The DHET also responded by revising its old Policy for Measurement of Research Outputs of Public Higher Education Institutions (2003) with a new Research Outputs Policy, 2015. The new policy specified:

Research output is defined as textual output where research is understood as original, systematic investigation undertaken in order to gain new knowledge and understanding. Peer review of the research is a fundamental prerequisite of all recognised outputs and is the mechanism of ensuring and thus enhancing quality.

and

Peer Review is understood to be the pre-publication refereeing or evaluation of complete manuscripts by independent experts in the field in order to ensure quality and determine whether manuscripts are publishable or not. (DHET 2015, p. 4)

The policy now expressly indicates the funding formula and research subsidy protocol to be applied. It offers clarity on, amongst other issues, the distribution of research subsidy to public higher education institutions, journal and book vetting criteria, the audit criteria to be applied to institutional submissions for subsidy claims, and that the accredited list of journals shall be subject to annual review. Of particular note though is that, in financially rewarding research production through this incentive scheme, it inadvertently continues to nourish a competitive, neoliberal culture in which research production is quantified, measured, and rewarded. The effect of this seemingly innocent funding framework is discussed later.

In the discussion that follows, I provide an account of the issue of judgement as a taken-forgranted phenomenon, my neglect of this crucial phenomenon as a taught (and learned) holistic competence as I undertake my work as supervisor of advanced research students, and my own casual and uncritical engagement with the issue. 


\section{Public judgement as necessary precondition in the scholarly space}

In this section I draw attention to the often neglected fact that, when one embarks on master's or doctoral study or when one engages in scholarly research and publication, one should see oneself as deliberately and consciously stepping into a very public arena in which there, literally, is no place to hide. Any claim one makes is fair game for public scrutiny and judgement. Kamler and Thomson reminded us that disciplinary knowledge fields are "occupied" territories that are "patrolled" by vigilant guardians (2006, p. 29) who rigorously apply the peer-review process. This process of judgement is in some instances confined and occurs in closed quarters in research proposal defences, for example, where just the professoriate engage the evaluation exercise (Lamont, 2009). The process of judgement, then, refers to the evaluation of evidence to make a decision. In the academic space, judgement is often used synonymously with the term critique. Critique usually comes before judgement. So critique would be a detailed analysis of something (in academia it's usually written pieces) with a view to arriving at a judgement of its standard and quality.

In undergraduate programmes, students' work (tests and assignments and examinations) are usually privy to just a few individuals-normally, the lecturer who is also the marker and possibly an external examiner-so, this can be described as a relatively private matter between the student and the lecturer. Students' work at this level is seldom subject to public display and scrutiny. In contrast, at master's and doctoral level, and in the world of the academic researcher, the terms of reference as related to assessment and examination of scholarly artefacts are dramatically different. At this level, students have to work, in many instances, exclusively as individuals, however, the assessment protocols at these levels are significantly more public. Knowledge production at this level is subject to validation by established peers in the academic community who decide whether or not to admit the novice researcher as a member of the disciplinary community. Academic peers decide whether a student should pass or fail or whether your article or book gets published or not. This gatekeeper work and boundary protection is very necessary because it safeguards the academic integrity of new knowledge proposals by enforcing minimum standards of academic rigour. What is expected is that one learns the rules of the academic game (Kamler \& Thomson, 2006). Of note, is that the primary overarching principle is that it has to necessarily be a space shaped by critique and judgement. That this has played itself out in sometimes unhealthy ways, historically, is a moot point. That millions of feelings have been hurt and egos shattered, and self-esteem questioned, is a lived reality that many academics and students will attest to.

The learning point here is that academics (me, included) do not do enough of the necessary preparatory work for receiving critique and dealing with judgement. Supervisors, for example, in offering critique might well pay attention to helping students develop emotional competence to embrace this world of critique. This also applies to preparing students for the various outcomes (pass, resubmit, or fail) of their thesis examination. This even extends to 
supervisors preparing themselves for different kinds of outcomes. When the outcome or result is positive, there is no problem, but when the thesis is returned and the report from the higher degrees committee is negative, requiring major review of the thesis, for example, this kind of public critique can be quite disconcerting both to the student and the supervisor. Opinions might quickly be formulated on the competence of the supervisor and the quality of supervision. The question of who is being judged arises - is it the student or is it the supervisor? (Note that this is not meant to over-simplify what might be a more complex answer). The key point is that learning how to manage oneself in a world where judgement is the norm is a competence we should be giving considered attention to. The post-panoptic, ocular archetype, that of postgraduate research super-vision (Lee \& Green, 2009), has resonance as it speaks to the constant scrutinising gaze of the world of scholarship. Living in the gaze is a competence tool that one has to keep constantly sharp and that one has to engage in deliberative teaching of, even to advanced research students. From my experience of working with research students for more than a decade, I have come to realise that when students sign up (officially register) for an advanced research degree, very few have given thought to the fact that they have unwittingly or unknowingly chosen to enter a very public space. Many may also not have constructed themselves as scholars and thinkers in the disciplinary fields they have chosen to be experts or authoritative in. More importantly, many may also not have conceived of themselves as knowledge producers. This is a crucial point that is worthy of deeper elaboration.

In many academic spaces (workshops, seminars, etc.) where the question as to why people choose to do a master's or doctoral study is posed, the reasons offered are often varied and can range from simply wanting the certificate for status enhancement. Others, especially some in academia, feel forced or under pressure from their institutions to undertake and complete doctoral studies. This latter reason is usually linked to the institution's goal of increasing their $\mathrm{PhD}$-qualified staff — to get its ratios right and, some might argue, improve its profile in the university rankings circus.

Very seldom does one hear from the institution a more sophisticated rationale for conducting high-level master's and doctoral study, a rationale where the individual constructs herself or himself as inquisitive, potential producer of new knowledge. I want to emphasise how important this kind of nuanced understanding is because it is precisely a lack of this kind of understanding that may lead one to placing one's work in the wrong (dubious) places. In extending this more sophisticated understanding, namely, that one's research ought to contribute to the body of knowledge (a phrase that is sometimes used loosely), it becomes important to unpack what this really means. Well, it firstly means that one has to have a solid and intimate knowledge of the field one is working in or the phenomenon one has chosennot just a documentation of the state of knowledge, but an intimate knowledge thereof (see Jansen, 2011) with the view to arguing for how one's research and new knowledge produced adds to the lineage, to the heritage.

Unfortunately, what happens in the contemporary higher education space is that we have, through the multiple performance measurement mechanisms (Maistry, 2015), deviated from 
the fundamental reason why one should decide to write up an article. Very often, our rationale is wrongly located in the surveillance machinery that monitors our performance, our research production, and usually in somewhat problematic calendar year intervals. So we might do it for this reason, for fear of being judged as performing below the expected norm (UKZN, for example, is notorious for annually circulating research productivity "league tables" of its academic staff). In reflecting on my own practice and my local institutional context, it is evident that we neglect the more sophisticated conversations amongst ourselves as academics and with our students as to why we do research and why we publish. This has been a particularly steep learning curve for me, namely, disrupting my preoccupation with producing outputs as opposed to constructing myself as organic knowledge producer.

\section{Tracing the events that led to my unravelling: The cost of blissful ignorance}

As mentioned earlier, from 2012-2014, I published five articles with KRE, a publisher that has now been identified by Beall and others as a predatory publisher. This was a mistake of huge proportion, which has resulted in serious personal reputational damage. The faux pas overshadows the 30+ articles I have in reputable spaces, my 16 successfully graduated doctoral students, and 11 master's students. At the time, KRE was on the International Bibliography of Social Sciences list — one of the lists recognised by the DHET, and it is evident that the DHET also had no knowledge of the practices of this publisher. The same can be said for my institution, the University of KwaZulu-Natal. Having served in a middlemanagement leadership position for five years (as Head of School and as Cluster Leader) from 2010-2014, and having sat through numerous executive committee meetings, and at UKZN senate for three years, while I was aware that some journals were more prestigious than others, I can say with a fair degree of certainty that the concept predatory journal was not an issue that featured in the discourse at this institution during this period. In fact, an active scholar in the school had secured a special edition of an international journal managed by this publisher - an "accomplishment" we were quite proud of at the time. A public call for papers went out. This colleague sits on the board of other journals and followed a due peerreview protocol. In hindsight, I realise that we failed to do our due diligence on this publisher, and had not recognised the profit motive enterprise of this publishing house. The oblivion of my institution was evident in the fact that UKZN's research office willingly paid the publishing costs of this special edition.

Another telling example of the level of blissful ignorance at play was the public exhibition of research publications on the notice board of the foyer of the school of education. This is common practice across many universities. It is a public, tangible showcasing of the knowledge production of staff. I personally have not engaged in this kind of advertising but, at any point in time, there would certainly have been a good number of publications (of other colleagues) that have now been declared predatory. Over the years, large numbers of different people including students, academics, international researchers, deans, and vice-chancellors have stopped and admired these accomplishments. The school even hosted national and 
international conferences in the space. This might well be described as the proverbial lull before the storm.

Note though, that the ultimate responsibility lies with the academic to do the necessary background check on a publishing house. Two of those pieces I published were with colleagues at UKZN, a collaboration that I now sincerely regret, given the negative exposure I have inadvertently subjected them to. I was rewarded by the university as per its research outputs reward system, which currently stands at R18,000 per article or book chapter. The benefit amounted to R72,000 - the quantum that the university transferred into my research cost centre. I have been in communication with my dean to have these funds transferred back to the university or to utilise them in ways that the school deems fit (capacity development, etc.). That was the easy part. Dealing with the stress and anxiety of losing one's academic reputation is the more painful price I am having to pay. It has become evident that my institution has not figured out how to manage my proposal for "paying back the money" in lieu of my transgression. The idea of deploying these funds to support developing researchers has received support. The political precedent might, however, have ramifications for how the institution applies (or does not apply) the measure to other "complicit" colleagues.

\section{So, what have been the real consequences?}

The first immediate material consequence that shook my foundations was observing in writing (a tangible artefact), the negative outcome of my re-rating application to the National Research Foundation (NRF). I was not re-rated. While I knew that these tainted publications existed in my oeuvre, I was yet to be publicly judged for this. In fact, I felt it prudent not to include these condemned pieces in my application to the NRF. I later learned that it may have been perceived as deliberate concealment, and served as compelling reason to deal with this in the public domain. For me though, not being rated was the least of my concerns (even though it now excludes me from competing for specially earmarked funds for rated researchers). The loss of credibility and standing in the academic community is by far the higher cost to bear.

The notion of deliberate concealment certainly touched a raw nerve with me. I might well describe it as an encounter with the Lacanian Real (Žižek, 2011), an inexplicable sensation, beyond the possibilities of language. It is when a human subject experiences a life altering moment, a realisation of one's inescapability from a raw and potentially violent vulnerability - a succumbing to a force that is beyond comprehension. It startled me as I started to comprehend the visceral facticity of how my world was going to change. I started to realise that there was an element of truth in this. It was what I had in fact been doing-a concealing from my various other associates in academia. Here I include my research students, colleagues who co-supervise with me, colleagues who coauthor with me, the editors of the journals on whose boards I serve as adviser, other higher institutions I am associated with (for example, Rhodes University for whom I undertake research capacity development programmes across various institutions in South Africa, and Umalusi for whom I have undertaken research in their name), and even people who use me as a referee for job 
applications and other scholarly reviews. There are likely to be more people who might be affected or compromised, all of whom I will accord the respect they deserve, that is, having complete knowledge of my research profile and deciding how they wish to approach our future relationship. I have started the process of doing this.

\section{And what can we learn from this?}

That it is really important to give due attention to where we choose to publish, seems to be the obvious learning point. But it goes well beyond that, it raises several other pertinent issues.

In the first instance, it might be useful to examine the structural push factors that drive particular behaviours of academics in the South African higher education context. One distinct factor is the encroachment of neoliberal performativity regimes in the higher education space. University academic (and non-academic) personnel in South African higher education institutions are increasingly being subjected to performance management regimes. These regimes have been borrowed from industry and foisted upon the academic sector. Academic personnel have had limited power to resist this onslaught. The rich qualitative work of university academics has been reduced to measurable "quantifiables." At the University of KwaZulu-Natal for example, the work of academics is measured annually through a "sophisticated" performance management scheme and workload formula that can measure the four generally "accepted" aspects of a typical academic's workload, namely, teaching, research, community service, and administration in a 45:40:10:5 general proportional distribution. The research dimension of an academic's work is measured according to productivity units that the academic generates. Such productivity units are earned through graduating master's and doctoral students and through research publication (and other recognised scholarly outputs such as patents, etc.) in DHET-accredited or approved journals and books. Academics at lecturer level have to produce the equivalent of one journal article per annum, senior lecturers, one and a half articles, associate professors, two articles and full professors two and a half articles. These research output yardsticks are strictly applied in determining an academic's performance score on a scale of one to four.

The consistent attainment of these rank-related yardsticks also determines an academic's eligibility for promotion. The financial incentive scheme for research production works on two levels. High-performing academics who obtain a high score (3 or 4), receive a 14th cheque, a monetary reward distributed from a pool designated for this. The second more lucrative level, is receipt of R18,000 per published article that is paid into the academic's research cost centre to be used to defray research-related expenditure (conference fees, etc.). Research productivity league tables are circulated publicly on the university internal communication system. High-performing academics are commended and rewarded (promoted). Those who do not meet their research productivity target performance are named and shamed, referred to as under-performers, threatened with higher teaching workloads, and cajoled into developing a research publication ethic (see Maistry, 2015 for a full analysis of how the accountability and surveillance mechanism works at UKZN). 
In essence, two push factors are at play when it comes to explaining the drive to publish. One, a lucrative reward for research publication system and, the second, a surveillance and accountability system set up in a way that is punitive. Both these factors, however, detract from the more profound and academically sound arguments for why academics should engage in research, a discussion of which follows later.

It is beyond the scope of this article to analyse in any detail the nature of the South African national research productivity incentive scheme. Of note though is that universities depend on research productivity funding for their sustainability, and actively compete for their share of this funding pie. In fact, the same neoliberal performativity principle is at play at the national level. Similar research production league tables are on public display. High research productivity universities use this kind of positioning strategically as public relations and marketing levers to attract personnel, students, even more funding, and to strengthen their profiles and positions on the multiple international rankings machinery. It follows that a financially expedient, instrumental rationale for research is at work at a macro level, with different universities employing varying local incentive distributional mechanisms, some rewarding individual academics with cash-in-the-pocket schemes, some (like UKZN) reward individually but retain control of funds at an institutional level, and others work on a department or faculty communal pool model to which individual academics may lodge a claim. The South African higher education research productivity incentive scheme thus presents as an area ripe for critical research as the current system of reward and punishment at both the macro and micro levels has triggered certain behaviours, one of which was the lure of easily accessible research publication in predatory journals.

It is clear that some academics seized the opportunities that presented at the time, used certain locales for research dissemination (predatory publishing houses) for a significant period of time, and that during this time universities were content with harvesting state funds even though the sites of dissemination had tarnished profiles. As stated earlier, the argument of blissful ignorance at an institutional level (university senates and research committees, astute custodians and moral gatekeepers of university knowledge production) is unacceptable. A degree of complicity lies at the door of DHET for what might be regarded as negligence related to periodically reviewing their accredited journal lists and researching international publishing practices with the view to remaining alert to the global, competitive, profit-driven game that publishing houses are engaged in. South African academia and intelligentsia (organisations such as Academy of Science South Africa, etc.) might also be deemed culpable for not being sufficiently attuned to how the neoliberal, corporate machinery is at work both nationally and internationally. There has, however, been a rude awakening of late and attempts at damage control at various levels.

Arguably, the more compelling reasons for why universities and academics should engage with research gets over-shadowed by this neoliberal performativity agenda. Extraneous factors appear to have superseded the core argument for doing research, which is to advance knowledge in a discipline. So, academics who are immune to the extraneous neoliberal factors at play may posit more profound reasons for wanting to publish. When academics 
construct their identities as researchers and producers of new knowledge with a view to responding to disciplinary lacunas, they seek out avenues for knowledge dissemination that are credible (and where authentic research resides). Such academics value the rigour of the peer-review process (whether blind, double-blind, single-blind, or open) and understand that an important conduit for knowledge dissemination is through publication. That this profundity has eluded the average South African academic is indeed a moot point.

Predatory publishing has taken on different guises and remains a growing concern for the international academic community. At a local practical level, it ought to focus our attention on, for example, how much attention is paid to the sources of knowledge we cite. As supervisors, are we doing enough with our students to alert them to this, an issue I am now making standard practice. So for master's and doctoral students, it becomes crucial to become very familiar with this world of knowledge creation and dissemination, especially open access and online; crucial, that one ought not to blindly believe the claims by certain journals as to their impact factor and indexing credentials and about the composition of their editorial boards, and so forth. This caution applies equally to colleagues who are crafting their articles and book chapters.

I learned very recently about the traumatic experience of a young colleague who inadvertently cited in her article, work published in a space that has now been declared an unsavoury source. The reviewers were quite critical in their review reports, almost bordering on ridicule as they signalled this discovery. They believed that this colleague was offering validation and giving undue credence to work in these grey spaces. This caution also applies to master's and doctoral studies that go out for examination. One should expect that the work will be subject to intense scrutiny with respect to the literature one cites, and it follows that poor choices would unwittingly invite critique that would be really difficult to defend. It may well serve to dilute the academic value of research endeavour.

Research supervisors might have to reconsider nominating examiners whose curriculum vitae contain discrediting evidence. Higher degrees committees also have to give due consideration to a more scrupulous examination of this aspect of their important quality assurance work. The composition of the research and higher degrees committees now necessitates some considered discussion given that their membership may well comprise individuals whose credentials have now come into question. The ripple effect of this is profound because it has implications for the appointment of new colleagues to the university, promotion applications, the holding of senior management and leadership positions, and academic decisions as to who might be deemed credible supervisor. These are indeed very disconcerting issues to deal with, but issues that the higher education community cannot shy away from any longer. In fact, a distinct area begging robust scholarly investigation and more scrupulous examination is the other knowledge vetting processes and procedures at play in the South African academic environment.

It has been easier to pinpoint the more overt unhealthy practice of predatory publishing, but it is a lot more difficult to lead firm evidence about the less overt and unethical practices that have been pervasive in the South African research context, and that render the space fractious 
and fragile (Teferra, 2015). That unethical practices exist in academia is a moot point. Some of the less overt (covert) knowledge vetting protocols have been around for decades. The inside-track phenomenon, for example, has been widely and unashamedly employed for many years, where local academics have frequently used in-house journals to ramp up their research productivity. There is also the trend of journal editors regularly publishing in their own journals. It is only recently that DHET has instituted the maximum 25\% internal author limitation on in-house journals to counteract this practice. The inside-track phenomenon still applies.

There is also much anecdotal information on how and who gets nominated and selected as external examiners for master's and doctoral studies-that the foremost experts are not always selected, but amenable "pals" instead. The nomination of friends who write up generous review reports is not an uncommon practice in these knowledge vetting instances. These are the less overt hard truths that are seldom discussed in any critical fashion.

I want to extend the analysis to a further micro layer of knowledge production, one where supervisors are sometimes complicit in fractious practices. Consider the simple issue of giving feedback to master's and especially doctoral students. The nature and type of feedback on the draft chapters of research students is a significant determinant of who created the knowledge that appears in the thesis. Constructive, dialectical feedback allows students to take ownership of the knowledge creation process. However, if feedback is largely instructive, where the supervisor tells, prescribes or instructs, and corrects students' writing, then the ownership of that new knowledge might well be located with the supervisor and not the student (Carter \& Kumar, 2017). In some instances, supervisors take over the writingactually rewrite students' paragraphs. They take over and control the thoughts and ideas of the student; in other words, the supervisor is the key knowledge producer. Instructive feedback then, has certain implications for how learning happens as well as autonomy and ownership of the knowledge creation process. If feedback is entirely instructive and directive, a telling, the candidate is likely to follow due instruction and write up the thesis as directed (Carter \& Kumar, 2017). The location of authority and ownership of the new knowledge in, this instance, resides with the supervisor. Yet, this knowledge gets vetted by peers in the community as the student's work. While this argument might seem far removed from the primary focus of this article, it does speak to the need for a consistent application of principle to knowledge vetting in all of the knowledge production domains-and not just the overt and tangible.

\section{Some concluding thoughts...}

For colleagues like myself who find themselves in the line of fire as it relates to predatory publishing, there is no easy way to deal with this. Academia is a space inhabited by different kinds of beings, some who might be understanding, empathetic, and supportive, while others not so. Some, in their rightful quest to protect the integrity of their disciplines and academia in general might be quite unforgiving and very critical. One can react, get upset and angry, and offer a retort, or one can choose to maintain one's composure and respond. The position I 
have taken is not to defend my poor judgement. I realise that it is impossible for me to control the various opinions that are forming about me or the corridor talk-these are natural human reactions. I am also aware that the position I have taken on this might not find favour with other affected colleagues. As an academic, my integrity and credibility in the academic community is paramount.

In essence, it comes back to a deeper understanding and acceptance that in the academia one derives credibility and integrity not from self-promotion, or posturing, or going around telling the world how good one is. In academia, credibility and integrity are earned via the peerreview process (Kamler \& Thomson, 2006; Lamont, 2009). It is one's peers who determine whether one's work is credible or not—not one's spouse, children, or one's parents.

I am hoping that this self-critical exposé might be the first step in my demonstrable show of remorse. This is certainly not meant to be an arrogant disclosure. I am hoping that young academics might learn from my experience of having made poor choices. Opportunities to transgress and expose oneself to risk present themselves on a daily basis, and they often present with well-disguised authenticity. While transgression, even from a position of ignorance is inexcusable, my experience does make a convincing case for South African higher education institutions to take up, more seriously, the issue of mentorship of young academics, especially as it relates to the potential new perils that might present.

I want to now draw inspiration from contemporary Slovenian philosopher and cultural critic, Slavoj Žižek, and his advocacy for a shared obscene solidarity, a situation where one tells a dirty joke about oneself (Žižek, 2004, 2011). He argued that this exchange of tiny obscenities allows us to make a real human connection. So if someone came up to me after reading this article and said something like: "So you goat $f^{*}$ cker, which species are you going to $f^{*} \mathrm{ck}$ next?" I would not be offended. If anything, I would welcome it as an endearing, empathetic recognition of the emotional dung that I am currently experiencing.

Following my move to deal with this in the public space, there has been a flood of responses from colleagues across the country, with colleagues being quite clear about the fact that this was certainly a lapse in judgement and a poor choice, but also offering reassuring support. Some colleagues described it as brave but, for me, it was not about bravery-it was about doing what my instincts were telling me was the right thing to do, to assume full responsibility. I certainly do not feel brave. If anything, I feel much angst and grief, as if I have lost a part of me. One colleague commended me on coming out of the closet. This was an interesting comment given that this reference is usually reserved for people who publicly declare their non-normative sexual preference, which in reality they ought not to be apologising for. Mine, on the other hand, is a public confessional as a first demonstration of remorse for poor judgement.

\section{References}

Beall, J. (2013). Predatory publishing is just one of the consequences of gold open access. Learned Publishing, 26, 79-84. 
Bowman, J. D. (2014). Predatory publishing, questionable peer review and fraudulent conferences. American Journal of Pharmaceutical Education, 78(10), 1-6.

Boylorn, R., \& Orbe, M. (2014). Critical autoethnography: Intersecting cultural identities in everyday life. California, CA: Left Coast Press.

Carter, S., \& Kumar, V. (2017). "Ignoring me is part of learning": Supervisory feedback on doctoral learning. Innovations in Education and Teaching International, 54(1), 68-75.

Deleuze, G., \& Guattari, F. (1987). A thousand plateaus. Minneapolis, MN: University of Minnesota Press.

Department of Higher Education and Training (DHET). (2015). Research outputs policy, 2015. Pretoria, RSA: DHET. Retrieved from https://archive.opengazettes.org.za/archive/ZA/2015/government-gazette-ZA-vol597-no-38552-dated-2015-03-11.pdf

Ellis, C., Adams, T., \& Bochner, A. (2011). Autoethnography: An overview. Forum: Qualitative Social Research, 12(1), Art. 10.

Jansen, J. (2011). The quality of doctoral education in South Africa. Perspectives in Education, 29(3), 139-146.

Kamler, B., \& Thomson, P. (2006). Helping doctoral students write: Pedagogies for supervision. London, UK: Routledge.

Lamont, M. (2009). How professors think: Inside the curious world of academic judgement. Cambridge, MA: Harvard University Press.

Lassonde, C., Galman, S., \& Kosnick, C. (Eds.). (2009). Self-study research methodologies for teacher educators. Rotterdam, Netherlands: Sense.

Lee, A., \& Green, B. (2009). Supervisor as metaphor. Studies in Higher Education, 34(6), $615-630$.

Maistry, S. M. (2012). Confronting the neoliberal brute: Reflections of a higher education middle-level manager. South African Journal of Higher Education, 26(3), 515-528.

Maistry, S. M. (2015). Accountability and surveillance: New mechanisms of control in higher education. Transformation: Critial Perspectives on Southern Africa, 88, 25-35.

Miller, E., \& DeBerg, J. (2017). The perils of predatory publishing: Views and advice from an editor and a health sciences librarian. American Society for Pain Management Nursing, 18(6), 351-352.

Mouton, J., \& Valentine, A. (2017). The extent of South African authored articles in predatory journals. South African Journal of Science, 113(7/8), 1-9. 
Seigel, T. J. (2018). Predatory publishing: What authors need to know. Teaching and Learning in Nursing, 13(3), 156.

Teferra, D. (2015). Manufacturing and exporting excellence and "mediocrity": Doctoral education in South Africa. South African Journal of Higher Education, 29(5), 8-19.

Žižek, S. (Ed.). (2004). Revolution at the gates: A selection of writings from February to October 1917, V. I. Lenin. London, UK: Verso.

Žižek, S. (2011). Living in the end times. London, UK: Verso. 